\title{
International Foot
}

National Cancer Institute

\section{Source}

National Cancer Institute. International Foot. NCI Thesaurus. Code C71253.

A traditional unit of length defined by the U.S. National Bureau of Standards as 30.48

centimeters. It is equal to 0.3048 meter, 12 inches, or to approximately 0.999998 survey foot. 